\title{
DESIGN AND DEVELOPMENT OF HAND POWER TRICYCLE FOR DISABLED USING HAND LEVER AND CRANK SYSTEM
}

\author{
G Sarat Raju \\ Department of Mechanical Engineering, \\ Institute of Aeronautical Engineering, Hyderabad, T.S, India \\ A Somaiah \\ Department of Mechanical Engineering, \\ Institute of Aeronautical Engineering, Hyderabad, T.S, India
}

\begin{abstract}
The main objective is to develop efficient vehicle with affordable price and by using less effort to propel the vehicle. Style and manufacture a chair trike attachment for higher accessibility and performance of a chair user. This trike is incredibly with efficiency designed and might be proven as a stronger replacement for the autochthonal models employed by the incapacitated keeping in mind the factors like safety, value and performance. Trike for the handicap folks to be propelled by the novel link mechanism hooked up to the steering column changing into cranking, victimization the advantage of leverage, with correct balance and distribution of mass and centre of gravity to crank the wheel shaft for dynamical. As he will use each the hands on the steering, higher management of the vehicle is ensured. The user will go quicker and farther (in out of doors use). Levers area unit ergonomically higher for the user (less body stress induced by propulsion forces then for push rim).
\end{abstract}

Keywords: Trike wheel, Steering PRN, Mechanism, Novel link.

Cite this Article: G Sarat Raju and A Somaiah, Design and Development of Hand Power Tricycle for Disabled Using Hand Lever and Crank System. International Journal of Mechanical Engineering and Technology 11(2), 2020, pp. 92-98. https://iaeme.com/Home/issue/IJMET?Volume=11\&Issue $=2$

\section{INTRODUCTION}

Transportation is one of the important factors in our day-to-day life, but for normal person it is very easy to go from one place to another place and this is very difficult for the handicapped person. In the world almost 100-130 million people need wheelchair. Handicapped person normally use tricycle that work on the chain and sprocket mechanism it operated by hand, but it has some disadvantages. Motorized tricycle is also developed, but now a days the price of fuel is increase rapidly and pollution is also increase rapidly. So, this type of tricycle is very useful for handicapped as well as normal people. Current wheelchair 
technology is relatively well established, but price is also increase with new technology. So, in our tricycle we are using the slider crank mechanism. The slider crank mechanism is attached to the one of the rear wheel of the tricycle and one wheel is free to rotate. Steering propulsion system required less effort to move forward than the chain and sprocket mechanism. This tricycle is moving in forward and backward direction also. It can be stop without applying brake only by keep steering steady. There are plenty of styles of each design; the problem is that the tricycles tend to be heavy and very expensive. Physically handicap tricycles are favored by children and senior adults for their apparent stability versus a bicycle; however a conventional trike has poor dynamic lateral stability, and the rider must take care when cornering to avoid tipping the trike over.

\section{LITERATURE REVIEW}

This type of project is operated by hand with the assistance of a slider crank mechanism by swinging the steering column; thence it's low value (affordable) and having smart management. The mechanism reduces the hassle needed high propel the vehicle and additionally will increase the management as a result of the motive force are going to be holding the steering handle with each the arms [1].

Mobility of physically disabled persons is regarding social issue today. Varied hand driven tricycles, wheelchairs, retrofitted vehicles etc. area unit ordinarily out there for disabled folks as a mode of transportation. The fundamental trike may be a 3 wheeled style, pedalled by disabled persons within the aspect and seat within the middle of sitting arrangement. They use only 1 hand to steer the handle as a result of alternative hand is employed to rotate the pedal [5].

This is one seater 3 container for handicap person with front wheels being steered by the steering column. The steering column has the outer tube that is hinged at the bottom and also the alternative aspect extension of the steering column is propulsion and pushing the cranking mechanism of the rear wheel. the interior rod of the steering column is hinged to the link mechanism to the front wheel to steer the wheel as a steering handle is being turned that is control at the highest aspect of the steering column. The steering column is holding the steering rod among the bearings.

\section{MAJOR COMPONENTS OF TRICYLCE}

\subsection{Steering System}

Steering column that fulfils two purposes one is to give motion to the output wheel and other is to steer the cycle in desired direction. The steering column is pivoted to the base of the cycle. This steering column is pushed and pulled by human arm which imparts oscillating motion to the lever. The oscillating motion is then converted into rotary motion by cranking mechanism.

\subsection{Crank Mechanism}

The cranking mechanism consists of one crank and connecting rod. The crank is connected to wheel hub and connecting rod is fixed to steering column. When the steering column oscillates the connecting rod reciprocates and rotates the crank connected to it will further rotates the wheel. It is same as the fuel powered engine in which reciprocating motion of piston is converted to rotating by crank but the only difference is in this cycle oscillating is converted to reciprocating by crank and motion is given by human As this tricycle does not contain any chain drive mechanism or gear pairs which has direct surface contact amongst them so the friction is less and less effort is required. 


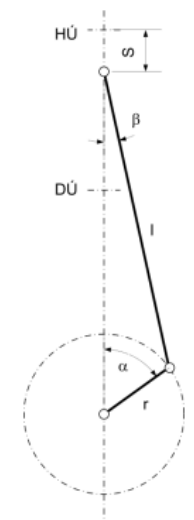

Figure 1 Slider Mechanism

\subsection{Caliper Mechanism Braking}

This is a rim brake during which friction pads are compressed against the wheel rims, hand operated brake lever, force is applied to brake levers mounted on the wheel, and transmitted via Bowden cables, that apply pressure to the braking surface, inflicting friction that slows the bicycle down.

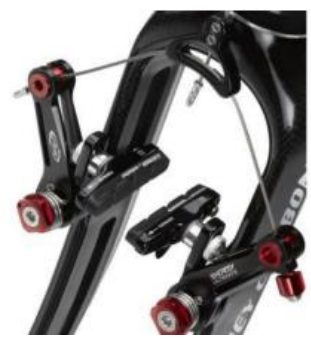

Figure 2 Caliper Mechanism Braking

\subsection{Universal Joint}

A universal joint (universal coupling, U-joint, Cardan joint, Spicer or Hardy Spicer joint, or Hooke's joint) is a joint or coupling connecting rigid rods whose axes are inclined to each other, and is commonly used in shafts that transmit rotary motion. It consists of a pair of hinges located close together, oriented at $90^{\circ}$ to each other, connected by a cross shaft. The 7 universal joint is not a constant-velocity joint. Universal joints come in a wide variety of shapes, sizes and configurations to accommodate the infinite amount of applications they can go into. Single Universal Joint It has only one bending aspect and is capable of operating at up to a 45-degree angle. Double Universal Joint It utilizes two bending joints; the double ujoint can operate at angles up to 90 degrees. Additionally, it also accommodate parallel offset between two shafts with an operating angle of the central section from 0 to 45 degrees.

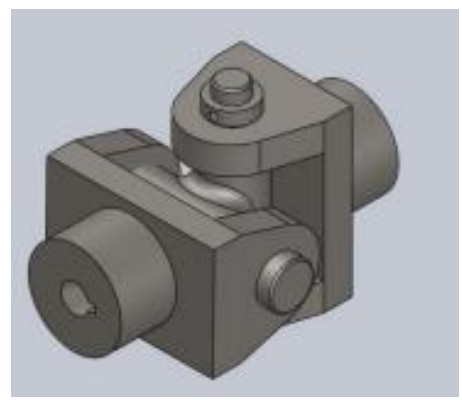

Figure 2 Caliper Mechanism Braking 


\section{MANUFACTURING PROCESS}

Once the design is finalized, a complete 3-D CAD model was developed in SOLID WORKS. An effort has been made to use off the shelf parts, but the fact that this hasn't ever been done means that it is still a very manufacturing-intensive project. Prior to manufacturing, the final design met all of the specifications and requirements. Since there were no problems with the 3-D CAD model, we proceeded on to manufacturing. The final design incorporated many parts that were available off the self, but it also included a lot of custom machined and fabricated parts. Manufacturing was split up between the front hand cycle attachment and the rear wheelchair section. The most important part of the tricycle is the structured base frame, which links the components together in the proper geometric configuration. The frame provides strength and rigidity to the tricycle and largely determines the handling of the tricycle. The square pipes are assembled into a frame by arc welding.

\section{MATERIAL PROPERTIES}

The structured base frame is made of AISI 1020 square pipes. AISI 1020 AISI 1020 is a low hardenability and low tensile carbon steel with Brinell hardness of 119 and tensile strength of 410-890 MPa. It has high machinability, high strength, high ductility and good weldability. It is normally used in turned and polished or cold drawn condition. Due to its low carbon content, it is resistant to induction hardening or flame hardening. Due to lack of alloying elements, it will not respond to nitriding. However, carburization is possible in order to obtain case hardness more than Rc65 for smaller sections that reduces with an increase in section size. Core strength will remain as it has been supplied for all the sections. Alternatively, carbon nitriding can be performed, offering certain benefits over standard carburizing. AISI 1020 steel can be largely utilized in all industrial sectors in order to enhance weldability or machinability properties.

\subsection{Chemical Composition}

The chemical composition of AISI 1020 steel is: Element Content Carbon, C $0.18-0.230 \%$ Iron, Fe 99.08 - $99.53 \%$ Manganese, Mn 0.30 - $0.60 \%$ Phosphorous, $\mathrm{P} \leq 0.040 \%$ Sulphur, S $\leq 0.050 \%$.

\subsection{Mechanical Properties}

The mechanical properties of AISI 1020 steel are:

$\begin{array}{lll}\text { Mechanical Properties } & \text { Metric } & \text { Imperial } \\ \text { Hardness, Brinell } & 111 & 111 \\ \text { Hardness, Knoop (Converted from Brinell hardness) } & 129 & 129 \\ \text { Hardness, Rockwell B(Converted from Brinell hardness) } & 64 & 64 \\ \text { Hardness, Vickers (Converted from Brinell hardness) } & 115 & 115 \\ \text { Tensile Strength, Ultimate } & 394.82 \mathrm{MPa} & 58249 \mathrm{psi} \\ \text { Tensile Strength, Yield } & 294.84 \mathrm{MPa} & 42848 \mathrm{psi} \\ \text { Elongation at Break (in 50 mm) } & 36.5 \% & 36.5 \% \\ \text { Reduction of Area } & 66.0 \% & 66.0 \% \\ \text { Modulus of Elasticity (Typical for steel) } & 200 \mathrm{GPa} & 29000 \mathrm{ksi} \\ \text { Bulk Modulus (Typical for steel) } & 140 \mathrm{GPa} & 20300 \mathrm{ksi} \\ \text { Poisson Ratio } & 0.290 & 0.290\end{array}$




\section{MECHANICAL DESIGN}

Calculation with Total Weight

Weight of the tricycle $=40 \mathrm{~kg}$

Weight of the disable person $=70 \mathrm{~kg}$

Diameter of the wheel $=45 \mathrm{~cm}=0.45 \mathrm{~m}$

$\mathrm{N}=90 \mathrm{rpm}$

\section{Angular Velocity}

$$
\begin{aligned}
w & =\frac{2 \pi N}{60} \\
& =\frac{2 * \pi * 90}{60} \\
& =9.4248 \mathrm{rad} / \mathrm{sec}
\end{aligned}
$$

\section{Velocity}

$$
\begin{aligned}
\mathrm{V} & =w^{*} \mathrm{r} \\
& =9.4248 * 0.23 \\
& =2.1677 \mathrm{~m} / \mathrm{sec} \\
& =7.8037 \mathrm{kmph}
\end{aligned}
$$

\section{Total force $=$ Total weight}

$$
=1079.1 \mathrm{~N}
$$

\section{Force on Each Wheel}

$$
\begin{aligned}
& \mathrm{F} 1=\mathrm{F} 2=539.55 \mathrm{~N} \\
& \text { TORQUE }=\mathrm{F} 1 * \mathrm{R} \\
& =539.55 * 0.23 \\
& =124.0965 \mathrm{Nm}
\end{aligned}
$$

\section{COMPONENT SPECIFICATION}

\begin{tabular}{|c|l|l|}
\hline 1 & Frame material & AISI 1020 Low carbon steel \\
\hline 2 & Pipes used for the frame & $2.54 \mathrm{~cm} * 2.54 \mathrm{~cm}$ \\
\hline 3 & Wheel size (Radius) & $45.82 \mathrm{~cm}$ \\
\hline 4 & Connecting rod length & $56 \mathrm{~cm}$ \\
\hline 5 & Load Capacity & $80 \mathrm{Kg}$ \\
\hline 6 & Tricycle weight & $40 \mathrm{Kg}$ \\
\hline 7 & Nuts and Bolts & M8 \\
\hline 8 & No. of Spokes & 28 \\
\hline 9 & Tyre Used & Tubeless Tyre \\
\hline
\end{tabular}




\section{TECHINICAL SPECIFICATION}

\begin{tabular}{|c|l|l|}
\hline 1 & Drive & Rear wheel drive \\
\hline 2 & Mechanism used & Slider crank \\
\hline 3 & Maximum speed & $7.8037 \mathrm{Kmph}$ \\
\hline 4 & Torque & $124.0965 \mathrm{~N} / \mathrm{m}$ \\
\hline 5 & Force & $1079.1 \mathrm{~N}$ \\
\hline 6 & Power & $1.1696 \mathrm{KW}$ \\
\hline
\end{tabular}

\section{COMPLETE ASSEMBLY}

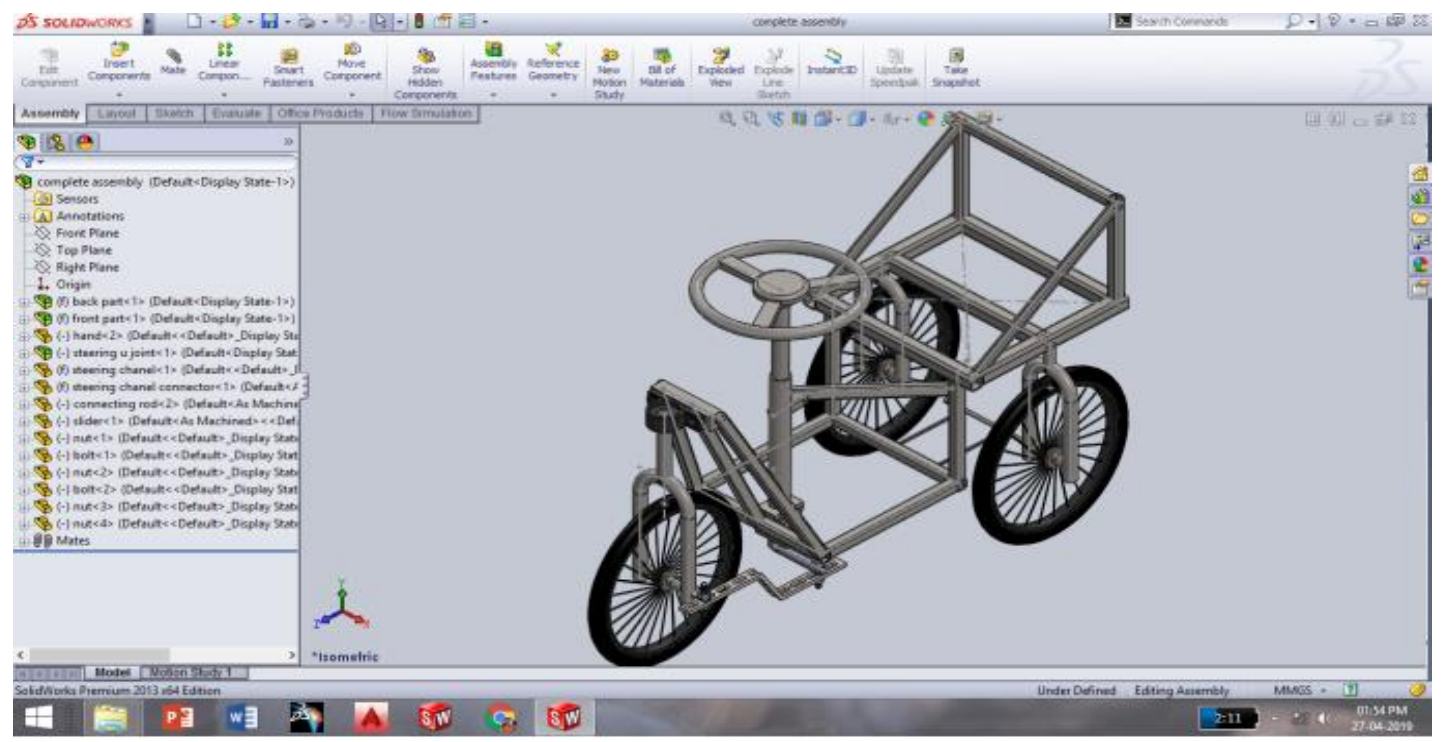

\section{CONCLUSION}

The hand cycle has evolved into a contemporary assistive device for sports, leisure and daily use, as well as for training, outdoors. Even in rehabilitation, hand cycling is being advocated as a good training alternative in early rehabilitation of also frail individuals. Within that context, there is a need for further research into optimal hand cycle design and fitting for different user groups. Apart from optimizing the wheelchair user interface, one needs to carefully consider maximizing overall work capacity of users and further reduction of the vehicle mechanical losses to ensure a real optimum level of mobility. It is expected that the current booming development of crank propelled tricycles in the industrialized countries serve not only the young and active wheelchair user, but also the less well-trained individual or those with more limitations that are extensive. In the end, the frequent active use of other than hand rim propelled wheelchairs may help prevent some of the secondary complications among the wheelchair user population today. What has been assumed until today, is a lower overall mechanical strain (in conjunction with a higher efficiency) in hand cycling compared to hand rim propulsion.

\section{REFERENCES}

[1] A Somaiah, K. Viswanath Allamraju, G.Sarat Raju and BLN Krishna Sai, Study of Innovative Regenerative Brake For Automobiles, International Journal of Mechanical Engineering and Technology, 8(8), 2017, 20-25. 
[2] Giuseppe Quaglia, Walter Franco and Riccardo Oderio, Wheelchair, Motorized Wheelchair with Stair Climbing Ability, Mechanism and Machine Theory, 46(11), 2011, 1601-1609.

[3] Murray J Lawn, Takakazu Ishimatsu, Modeling of a Stair- Climbing Wheelchair Mechanism with High Single Step Capability, 11(3), 2003, 323-332.

[4] Wang H, Salatin B, Grindle G G, Ding Dand Cooper R A, Real- Time Model Based Electrical Powered Wheelchair Control, Medical Engineering \& Amp. Physics, 31(10), 2009, 1244-1254.

[5] S. Dwivedi, D. Yadav, A. Mishra, M. Jaiswal, S. Singh, S. Kumar, Design and Fabrication of a Motorized Tricycle for Physically Challenged Persons, International Journal of Engineering Science Invention, 3, 2014, 29-32.

[6] V. Sreedhar, G. Ravi Chandra, T. N. Ravi Kanth and A Somaiah, Experimental Investigation on Shell and Tube Heat Exchanger Using Segmental and Disc-Doughnut Type Baffles, International Journal of Mechanical Engineering and Technology 8(12), 2017, 975-984.

[7] Hand Powered and Control" invented by Randall L. Harper from Lakewood, USA. 291978:US4109927. 